\title{
The evolution of the European Respiratory Journal: ready for the new decade!
}

\author{
James D. Chalmers ${ }^{1}$, Elin L. Reeves ${ }^{2}$, Neil J. Bullen ${ }^{2}$ and Martin Kolb $\mathbb{1}^{3}$ \\ Affiliations: ${ }^{1}$ Division of Molecular and Clinical Medicine, University of Dundee, Ninewells Hospital and \\ Medical School, Dundee, UK. ${ }^{2}$ European Respiratory Society, Publications Office, Sheffield, UK. ${ }^{3}$ Dept of \\ Respiratory Medicine, Pathology and Molecular Medicine, McMaster University and St Joseph's Healthcare, \\ Hamilton, ON, Canada.
}

Correspondence: Martin Kolb, Dept of Respiratory Medicine, Pathology and Molecular Medicine, McMaster University and St Joseph's Healthcare, Hamilton, ON, Canada. E-mail: kolbmamcmaster.ca

@ERSpublications

The ERJ editors wish all readers, authors, reviewers and editors a happy and successful 2020, and are ready to continue their work into the new decade! http://bit.ly/36AbocX

Cite this article as: Chalmers JD, Reeves EL, Bullen NJ, et al. The evolution of the European Respiratory Journal: ready for the new decade! Eur Respir J 2020; 55: 1902503 [https://doi.org/10.1183/ 13993003.02503-2019].

It has already been 2 years since we took the privilege of leading the European Respiratory Journal and we want to wish all of our readers, authors, reviewers and editors a very happy and successful 2020. It has been another busy and successful year at the journal.

\section{Highlights from 2019}

The year started with publication of the proceedings of the $6^{\text {th }}$ World Symposium on Pulmonary Hypertension, providing key updates on pathogenesis, genetics, diagnosis and treatment of all classes of pulmonary hypertension [1-14]. The World Symposium has been held every 5 years since 1973 and the proceedings provide comprehensive guidance on the state of the art in pulmonary vascular disease. This series was published in the ERJ for the first time in its 45 -year history, and perhaps the most impactful article of the series was that on the new haemodynamic definitions and updated clinical classification of pulmonary hypertension [5]. This document proposed a threshold of pulmonary artery pressure $>20 \mathrm{mmHg}$ to define clinically significant disease. Whether or not this new threshold should lead to a rewriting of the textbooks of medicine was addressed in a pro/con editorial a few months later, and generated significant debate [15-20]. The series further discussed future clinical trial design and also the critical impact of patient perspectives $[9,14]$. The entire series was published open access in acknowledgement of the critical nature of these articles for the global pulmonary community.

The ERJ has two regular review series: "state of the art", which aims to give a high impact current update on key clinical and translational topics; and "back to basics", which provides accessible reviews of basic and translational science topics [21, 22]. 2019 saw a focus on COPD, with reviews and perspectives focused on controversial topics, including the role of inhaled corticosteroids, early COPD, and imaging and biomarkers [23-25]. Precision medicine in COPD and airways disease continues to develop and will have more and more impact on clinical respirology in the near future [26-28]. One major aspect is the question about how to assess airway inflammation in practice. The Global Initiative for Chronic Obstructive Lung Disease (GOLD) science committee published the justification for the recent GOLD strategy update in 2019, explaining the decision to include blood eosinophils in the decision-making process for use of inhaled corticosteroids for the first time [29]. Treatable traits, a concept originally 
published in the ERJ in 2016, are not only of relevance for COPD, but also asthma, as reported by the Australian/New Zealand "Down Under International Workshop" [30-32]. Further, the Global Initiative for Asthma (GINA) executive committee published the highlights of their 2019 guidelines in an important editorial in June $[33,34]$. These new guidelines describe a fundamental change in asthma management, with GINA no longer recommending treatment of asthma in adolescents and adults with short-acting bronchodilators alone. Instead, GINA recommended that all adults and adolescents with asthma should receive either symptom-driven (in mild asthma) or daily inhaled corticosteroid-containing treatment. In recommending these changes, GINA recognised that there are questions to be addressed, including the cost of implementation in low- and high-income countries [33].

The third area we wanted to highlight is the debate and new evidence on the risk of electronic cigarettes [35-40]. The second half of 2019 featured numerous reports about vaping-associated acute lung illnesses in adolescents and young adults, particularly in the USA [39]. Recent case reports also describe chronic respiratory problems, such as hypersensitivity pneumonitis, due to the non-organic components in e-cigarettes [38]. While a large number of fatalities seemed to be associated with vaping of marijuana-related products, the lack of awareness of the potential harm of vaping in general is becoming increasingly apparent. The ERS Tobacco Control Committee published a key document outlining the European Respiratory Society's official position on electronic cigarettes just as the year ended [41]. This document clearly states the society's position, that the tobacco harm reduction strategy is based on well-meaning but incorrect or undocumented claims. The Committee wrote that "human lungs are created to breathe clean air, not reduced levels of toxins and carcinogens"... and as such, concluded that "the ERS cannot recommend any product that is damaging to the lungs and human health" [41]. Of note, while the $E R J$ is published by the ERS, the editorial process is totally independent of the society, and the article, just like any other, underwent vigorous external peer review.

\section{ERJ methods are taking off}

A successful new feature in the journal is "ERJ methods" which was introduced in 2018 to give a guide to readers on the diverse and sometimes complex methodologies used in our speciality [42-49]. These are short mini-review papers intended to give non-experts the information required to understand and interpret the basics of cutting-edge methods. In 2019 these were among the most consistently well read and downloaded articles in the journal. We welcome unsolicited submissions and are happy to receive informal enquiries about potential topics for future ERJ methods papers.

\section{Peer review}

Peer review is the central pillar of the quality of the journal, and we are grateful to all of the reviewers that have given their time voluntarily to the journal over the past year. This year in Madrid at the ERS International Congress we recognised four excellent reviewers with the 2019 ERJ peer reviewer awards. These colleagues were Beatriz Amat, Wei-jie Guan, Erik Klok and Paolo Spagnolo. Each had contributed multiple high-quality reviews to the journal and were presented with a certificate recognising their outstanding work at the editorial board dinner in Madrid. The ERJ also has a mentoring programme for early career members of the ERS, in which we have formed several "teams" of an experienced associate editor and a "junior" associate editor, who assess papers jointly and navigate them through the peer review process. This programme has been very attractive to the community, such that we received a stunning 90 applications for the limited number of available teams. Keep tuned for further opportunities to get involved with the work of the ERJ.

\section{Prepublication servers and preprints}

Here at the ERJ we are committed to keeping peer review time frames to a minimum, because we know how important it is that our authors can disseminate their work quickly and have their articles published in a timely manner. The ERJ is quick, with an average time from submission to decision of 18 days, but by its very nature peer review introduces a delay to the publication process even for papers that are accepted. Recent years have seen a rise in popularity of the preprint: publication of a complete scholarly article, usually on a dedicated preprint server, before the work has been peer reviewed and, in general, before submission to a journal. This enables article preprints to be made available for immediate distribution, often being used by authors to gain early feedback on their work, which may then assist in refining works prior to a formal journal submission being made. Preprint servers are not a new idea, with the widely used bioRxiv.org being launched in 2013 and recently being joined by multiple alternatives. In June 2019, medRxiv.org was launched, and is a joint venture between BMJ Publishing, Cold Spring Harbor Laboratory and Yale University. The SSRN (Social Science Research Network) is a platform operated by Elsevier, established 25 years ago, but has recently added medicine as a new discipline to its preprint portfolio, as both MedRN and, later, as Preprints with The Lancet. The latter is available as preprint service for articles submitted to The Lancet journal family. While preprints have been well accepted in 
other fields, such as physics, for many years, it has been controversial in the medical field primarily because of the risk of non-peer reviewed science being able to influence clinical practice. The major preprint servers, however, have safeguards in place, including clear statements that material is not peer reviewed. As a journal that adheres strongly to the recommendations and guidance of the International Committee of Medical Journal Editors, the ERJ willingly accepts submissions of articles that have appeared in preprint form, as will most other journals in our field. However, transparency when posting and citing works prior to peer review is essential. This will ensure researchers and readers have the information they need, in order to interpret and make informed opinions on the documents they read and cite in our field.

\section{Looking forward to 2020}

The ERJ is the flagship journal of the European Respiratory Society, the largest community of respiratory professionals in the world. As such, we have a responsibility to ensure that we publish the very best science and education and make the ERJ what its readers and authors want. We are proud of our current impact factor of 11.807, which is the second highest in the ERJ's history. With the high level of the ERJ comes intense competition for space and the ERJ acceptance rate remains at around $10 \%$ for original research and reviews. So, to those who contributed to the ERJ in 2019 we say "congratulations!". For those high-quality papers we sadly have to decline due to lack of space, the growth of the ERS family of journals provides an increasingly attractive option. We cherish our strong relationship with our partner journals, especially the European Respiratory Review and ERJ Open Research. The European Respiratory Review publishes primarily review articles and has achieved a remarkable first impact factor of 4.929 in 2018, and we expect it to further increase. ERJ Open Research is an open access journal for basic, translational and clinical research which follows the same rigorous peer review process as the other ERS publications. The ERJ is selective in which papers we recommend for transfer to these journals, only selecting papers we consider to be of high quality and interest. We encourage authors to take advantage of this option to publish within the ERS family of journals.

2020 promises to be another exciting year for the ERJ, with an upcoming state of the art series on asthma planned for later in the year, new ERS guidelines including the first "short guideline", a new initiative from ERS to fast-track key clinical topics by producing guidelines in less than 1 year compared to the usual 2-3 year cycle, and our usual mix of outstanding original research and reviews. While the ERJ publishes across the length and breadth of respiratory medicine we have issued specific calls for papers this year. We are honoured to partner with The Lancet Respiratory Medicine and the Journal of Cystic Fibrosis to host a session at the European Cystic Fibrosis Society conference and so welcome submissions of original research and reviews for presentation in this session. We also seek proposals for high-quality state of the art reviews and the editors are happy to informally discuss these with prospective authors.

We feel honoured to have to have the opportunity to review your work and guide the journal at this exciting time for our speciality. Bring on the new decade, the ERJ team is ready for the future!

Conflict of interest: J.D. Chalmers has received research grants from GlaxoSmithKline, Boehringer Ingelheim, AstraZeneca, Pfizer, Grifols, Bayer AG, Polyphor and Insmed; and received consultancy, congress travel or speaker fees from GlaxoSmithKline, Bayer Healthcare, Aradigm Corporation, Grifols, Pfizer, Boehringer Ingelheim, Napp and Insmed. E.L. Reeves is an employee of the European Respiratory Society. N.J. Bullen is an employee of the European Respiratory Society. M. Kolb has received grants and personal fees from Roche, Boehringer Ingelheim, GSK, Gilead, Prometic and Alkermes; grants from Actelion, Respivert and Synairgen; and personal fees from AstraZeneca and Genoa.

\section{References}

1 Galie N, McLaughlin VV, Rubin LJ, et al. An overview of the 6th World Symposium on Pulmonary Hypertension. Eur Respir J 2019; 53: 1802148.

2 Humbert M, Guignabert C, Bonnet S, et al. Pathology and pathobiology of pulmonary hypertension: state of the art and research perspectives. Eur Respir J 2019; 53: 1801887.

3 Morrell NW, Aldred MA, Chung WK, et al. Genetics and genomics of pulmonary arterial hypertension. Eur Respir J 2019; 53: 1801899.

4 Vonk Noordegraaf A, Chin KM, Haddad F, et al. Pathophysiology of the right ventricle and of the pulmonary circulation in pulmonary hypertension: an update. Eur Respir J 2019; 53: 1801900.

5 Simonneau G, Montani D, Celermajer DS, et al. Haemodynamic definitions and updated clinical classification of pulmonary hypertension. Eur Respir J 2019; 53: 1801913.

6 Frost A, Badesch D, Gibbs JSR, et al. Diagnosis of pulmonary hypertension. Eur Respir J 2019; 53: 1801904.

7 Galie N, Channick RN, Frantz RP, et al. Risk stratification and medical therapy of pulmonary arterial hypertension. Eur Respir J 2019; 53: 1801889.

8 Hoeper MM, Benza RL, Corris $\mathrm{P}$, et al. Intensive care, right ventricular support and lung transplantation in patients with pulmonary hypertension. Eur Respir J 2019; 53: 1801906.

9 Sitbon O, Gomberg-Maitland M, Granton J, et al. Clinical trial design and new therapies for pulmonary arterial hypertension. Eur Respir J 2019; 53: 1801908.

10 Vachiery J-L, Tedford RJ, Rosenkranz S, et al. Pulmonary hypertension due to left heart disease. Eur Respir J 2019; 53: 1801897. 
11 Nathan SD, Barbera JA, Gaine SP, et al. Pulmonary hypertension in chronic lung disease and hypoxia. Eur Respir J 2019; 53: 1801914.

12 Kim NH, Delcroix M, Jais X, et al. Chronic thromboembolic pulmonary hypertension. Eur Respir J 2019; 53: 1801915.

13 Rosenzweig EB, Abman SH, Adatia I, et al. Paediatric pulmonary arterial hypertension: updates on definition, classification, diagnostics and management. Eur Respir J 2019; 53: 1801916.

14 McGoon MD, Ferrari P, Armstrong I, et al. The importance of patient perspectives in pulmonary hypertension. Eur Respir J 2019; 53: 1801919.

15 Gibbs JSR, Torbicki A. Proposed new pulmonary hypertension definition: is $4 \mathrm{~mm}(\mathrm{Hg})$ worth re-writing medical textbooks? Eur Respir J 2019; 53: 1900197.

16 Kovacs G, Olschewski H. Debating the new haemodynamic definition of pulmonary hypertension: much ado about nothing? Eur Respir J 2019; 54: 1901278.

17 Jaafar S, Visovatti S, Young A, et al. Impact of the revised haemodynamic definition on the diagnosis of pulmonary hypertension in patients with systemic sclerosis. Eur Respir J 2019; 54: 1900586.

18 Maron BA, Choudhary G, Tedford RJ, et al. Correspondence on the debate regarding the haemodynamic definition of pulmonary hypertension. Eur Respir J 2019; 53: 1900727.

19 Rosenzweig EB, Abman SH, Berger RMF. Response: Still puzzling about a clear definition of pulmonary arterial hypertension in newborns. Eur Respir J 2019; 53: 1900135.

20 Calcaterra G, Fanos V, Bassareo PP. Still puzzling about a clear definition of pulmonary arterial hypertension in newborns. Eur Respir J 2019; 53: 1900005.

21 Konigshoff M. The new Back to Basics section: emerging concepts in basic and translational medicine. Eur Respir J 2014; 44: 297-298.

22 Cowman S, van Ingen J, Griffith DE, et al. Non-tuberculous mycobacterial pulmonary disease. Eur Respir J 2019; 54: 1900250.

23 Leung JM, Sin DD. Inhaled corticosteroids in COPD: the final verdict is. Eur Respir J 2018; 52: 1801940.

24 Cazzola M, Rogliani P, Calzetta L, et al. Triple therapy versus single and dual long-acting bronchodilator therapy in COPD: a systematic review and meta-analysis. Eur Respir J 2018; 52: 1801586.

25 Soriano JB, Polverino F, Cosio BG. What is early COPD and why is it important? Eur Respir J 2018; 52 : 1801448.

26 Soriano JB, Ancochea J, Celli BR. The most beautiful COPD chart in the world: all together to end COPD! Eur Respir J 2019; 54: 1902047.

27 Lortet-Tieulent J, Soerjomataram I, Lopez-Campos JL, et al. International trends in COPD mortality, $1995-2017$. Eur Respir J 2019; 54: 1901791.

28 Suissa S, Ariel A. Triple therapy trials in COPD: a precision medicine opportunity. Eur Respir J 2018; 52 : 1801848.

29 Singh D, Agusti A, Anzueto A, et al. Global Strategy for the Diagnosis, Management, and Prevention of Chronic Obstructive Lung Disease: the GOLD science committee report 2019. Eur Respir J 2019; 53: 1900164.

30 McDonald VM, Fingleton J, Agusti A, et al. Treatable traits: a new paradigm for 21st century management of chronic airway diseases: Treatable Traits Down Under International Workshop report. Eur Respir J 2019; 53: 1802058.

31 Boaventura R, Sibila O, Agusti A, et al. Treatable traits in bronchiectasis. Eur Respir J 2018; 52: 1801269.

32 Agusti A, Bel E, Thomas M, et al. Treatable traits: toward precision medicine of chronic airway diseases. Eur Respir J 2016; 47: 410-419.

33 Reddel HK, FitzGerald JM, Bateman ED, et al. GINA 2019: a fundamental change in asthma management: Treatment of asthma with short-acting bronchodilators alone is no longer recommended for adults and adolescents. Eur Respir J 2019; 53: 1901046.

34 Boulet L-P, Reddel HK, Bateman E, et al. The Global Initiative for Asthma (GINA): 25 years later. Eur Respir J 2019; 54: 1900598

35 Reidel B, Radicioni G, Clapp PW, et al. E-cigarette use causes a unique innate immune response in the lung, involving increased neutrophilic activation and altered mucin secretion. Am J Respir Crit Care Med 2018; 197: 492-501.

36 Ferkol TW, Farber HJ, La Grutta S, et al. Electronic cigarette use in youths: a position statement of the Forum of International Respiratory Societies. Eur Respir J 2018; 51: 1800278.

37 Reinikovaite V, Rodriguez IE, Karoor V, et al. The effects of electronic cigarette vapour on the lung: direct comparison to tobacco smoke. Eur Respir J 2018; 51: 1701661.

38 Fels Elliott DR, Shah R, Hess CA, et al. Giant cell interstitial pneumonia secondary to cobalt exposure from e-cigarette use. Eur Respir J 2019; 54: 1901922.

39 Casanova GS, Amaro R, Soler N, et al. An imported case of e-cigarette or vaping associated lung injury (EVALI) in Barcelona. Eur Respir J 2019; in press [https://doi.org/10.1183/13993003.02076-2019].

40 Girvalaki C, Tzatzarakis M, Vardavas A, et al. Discrepancies in reported versus measured nicotine content of e-cigarette refill liquids across 9 European Countries before and after the implementation of the EU Tobacco Products Directive. Eur Respir J 2019; in press [https://doi.org/10.1183/13993003.00941-2019].

41 Pisinger C, Dagli E, Filippidis FT, et al. ERS and tobacco harm reduction. Eur Respir J 2019; 54: 1902009.

42 Watson RL, de Koff EM, Bogaert D. Characterising the respiratory microbiome. Eur Respir J 2018; 53: 1801711

43 Faner R, Sibila O, Agusti A, et al. The microbiome in respiratory medicine: current challenges and future perspectives. Eur Respir J 2017; 49: 1602086.

44 Dobler CC, Wilson ME, Murad MH. A pulmonologist's guide to understanding network meta-analysis. Eur Respir J 2018; 52: 1800525.

45 Cabibbe AM, Walker TM, Niemann S, et al. Whole genome sequencing of Mycobacterium tuberculosis. Eur Respir J 2018; 52: 1801163

46 Angelini E, Dahan S, Shah A. Unravelling machine learning: insights in respiratory medicine. Eur Respir J 2019; 54: 1901216

47 van Boven JFM, van de Hei SJ, Sadatsafavi M. Making sense of cost-effectiveness analyses in respiratory medicine: a practical guide for non-health economists. Eur Respir J 2019; 53: 1801816.

48 Hiemstra PS, Tetley TD, Janes SM. Airway and alveolar epithelial cells in culture. Eur Respir J 2019; $54: 1900742$.

49 van Mourik P, Beekman JM, van der Ent CK. Intestinal organoids to model cystic fibrosis. Eur Respir J 2019; 54: 1802379. 